\title{
A Numerical Study on the Impact of Wind Gust Frequency on Air Exchanges in Buildings with Variable External and Internal Leakages
}

\author{
Dimitrios Kraniotis *, Thomas K. Thiis and Tormod Aurlien \\ Department of Mathematical Sciences and Technology, Norwegian University of Life Sciences, \\ Ås 1432, Norway; E-Mails: thomas.thiis@nmbu.no (T.K.T); tormod.aurlien@nmbu.no (T.A.) \\ * Author to whom correspondence should be addressed; E-Mail: dimitrios.kraniotis@nmbu.no; \\ Tel.: +47-6496-6208; Fax: +47-6496-5401.
}

Received: 17 December 2013; in revised form: 20 February 2014 / Accepted: 21 February 2014 / Published: 5 March 2014

\begin{abstract}
Wind-driven air infiltration has been recognized among the major reasons for energy loss in buildings, and the impact to energy efficiency under steady conditions has been reported and issued as part of many building codes. The nearly zero-energy building demand makes uncontrolled leakage paths even more undesired and creates the need for further investigation of their behavior under unsteady wind conditions. The present numerical study examines the role of wind gustiness on instantaneous infiltration rates of a low-rise building. For this purpose, two levels of gust frequency $\Omega$ have been simulated, expressed as a sinusoidal factor in the wind profile formula. In parallel, a ratio $\alpha$ is employed to represent seven different cases of external leakages distribution, while five scenarios of compartmentalization and internal leakages shows the impact of the latter on the dynamics of building air exchange rates. The results indicate that higher wind gustiness results in higher $\mathrm{ACH}$, marking out gusts as a potential critical factor under unsteady climate conditions. The infiltration rates shown in relation to the leakage distribution ratio $\alpha$ provide arguments for the importance of the detailed detection of external leakages while the comparison of the different internal-volume-scenario highlights the key-role of internal leakages control towards a drastic reduction of infiltration rates.
\end{abstract}

Keywords: wind; air infiltration; leakage distribution; internal leakages; air flow; wind gust; computational fluid dynamics (CFD); transient analysis; Shear Stress Transport k- $\omega$ model (SST k- $\omega$ model) 


\section{Introduction}

Air infiltration in buildings refers to the uncontrolled or unintentional flow of outside air to the internal space through leakages in the envelope, typically cracks and/or large leakage points. From the 1970s onwards, its impact on energy performance has been recognized in the literature, e.g., [1]. Several studies have presented estimations of the heat load fraction in a building that takes place due to infiltration [2-10]. In addition, infiltration has been verified as playing an important role in the internal environment and in the indoor air quality [11-14]. The heating, ventilation and air conditioning system (HVAC) is also most likely influenced by high infiltration rates, resulting in an offset from the designed inner climate as well as in waste of energy [15]. Moisture problems have also been recorded due to leakage airflows (especially exfiltration) [16].

Air infiltration in buildings can be driven either by the wind-induced pressure differences across the envelope or by the gradients between internal and external temperatures (buoyancy pressures) or by the mechanical ventilation [17]. Analytical formulation of air infiltration caused by these mechanisms under steady state conditions has been investigated by Lyberg [18]. A detailed summary of applicable single-zone and multi-zone models for air infiltration and ventilation calculations has been presented by Orme [19]. In these models, the magnitude of wind as a driving force for infiltration is usually expressed by a typical value at a reference height (i.e., at the height of the roof), excluding the dynamic nature of the phenomena [20].

Physical models of the driving forces and their interaction with the building have been presented in order to estimate infiltration rates, based on the leakage numbers and climate indicators [21]. The main scope of these models is to calculate the average seasonal natural infiltration rates from the leakage rates as quantified by an artificial (fan) pressurization test at $50 \mathrm{~Pa}$ pressure difference across the building envelope [22]. The impact of wind is taken into account, but only in terms of mean wind speed.

However, especially in low-rise buildings, wind gustiness and the consequent pressure gradient on the facades seem to govern the air exchanges [23]. In general, openings exposed to turbulent wind can have a large impact on the variation of the internal pressure distribution in a building, affecting the airflow [24,25]. Flows through small cracks (leakages) can potentially cause unacceptable situations from an energy point of view [14]. Turbulence causing wind gustiness is recognized as one major factor that affects infiltration [26]. Turbulent fluctuating wind causes unsteady flow effects that are linked with the instantaneous airflow rates across cracks and openings and differ from the mean ones [27-29].

The dynamic characteristics of air infiltration was very early pointed out by Hill and Kusuda [30] who studied the unsteady flow phenomena through cracks around a single window. The whole rooms used in their study were completely sealed (apart from the window), limiting the results to a single-side infiltration case. A simple theoretical pulsation flow model of an enclosure with a single opening, subjected to turbulent impinging air stream, has been presented by Cockroft and Robertson [31]. In their study, the flow is caused by longitudinal fluctuations of wind and the compressibility of air within the enclosure. The study was focused on the single-side ventilation and it provided arguments on the percentage of the air flowing into the enclosure that contributes to the effective ventilation. Etheridge provided arguments in favor of the role of wind gustiness on the ventilation design field [32]. He analyzed the connection between gust strength and duration on one side and the effects of inertia and compressibility on the other side for a study dealing with large opening 
(vents and ducts) in a purpose-designed naturally ventilated building. A power spectrum analysis linearization technique for modeling pulsating airflow due to turbulent wind-induced pressures was executed by Haghighat and Rao [33]. They obtained good agreement between the model and their experimental results, but building crack geometries are not explicitly taken into account and the study deals with single-zone spaces.

In addition, leakage distribution has been mentioned as an important factor affecting the infiltration/ventilation rates [34-36] and models have been developed towards the estimation of leakage distribution [37]. In addition, the latter affects even the air pressure conditions in a building and the wind-induced internal pressure fluctuations [38,39]. In an analytical approach that allows the dynamic numerical simulation of infiltration and ventilation in buildings, based on Lyberg formulation and developed by Lowe, the assumption of uniformly distributed leakages on windward and leeward facades has been employed [40]. Furthermore, in that study, as well as in many of those mentioned above, the space of interest is a single-compartment building. However, apart from the external leakages, the internal leakage paths have been recognized as an important element towards the leakage rates when undertaking a pressurization test [41]. Recently, an analysis of infiltration rates in conjoined dwellings from the perspective of partition walls permeability was presented by Jones et al. [42]. The study provides arguments in favor of internal leakages consideration when the leakage-infiltration ratio is predicted, highlighting the significant variance the former can have. Clearly, predicting realistic air infiltration rates is a rather complex task, therefore assumptions and simplifications are usually employed in the models (e.g., steady-state conditions, mean wind speed, uniform leakage distribution, single-compartment spaces, etc.). The current study deals with the dynamics of the building air exchanges, aiming to inter-link the elements mentioned above (wind gust frequency, leakage distribution and internal leakages) in a low-rise one-story building. The numerical methods could contribute to an estimation of the impact of turbulent wind on air exchanges, through the simulation of potentially critical variable parameters of building envelope.

The paper focuses on wind-driven infiltration (buoyancy pressures are neglected and no mechanical ventilation system has been applied). Its major objective is to ascertain the influence of wind unsteadiness in the instantaneous infiltration rates through a transient analysis. In particular, the impact of wind gust frequency on the air in- and exfiltration rates of a cross-ventilated building-model with variable leakage areas. The role of the internal leakages is also studied and for this reason five different compartmentalization/partition-wall-permeability scenarios are researched. A computational fluid dynamics (CFD) solver that has been widely used in estimation of cross ventilation rates (SST k- $\omega$ ) is employed. The unsteady conditions (wind gust frequencies) are simulated as an additional sinusoidal factor in the wind profile formula. The accumulated infiltration rates over one hour $(\Sigma \mathrm{ACH})$ are calculated for the two wind gust frequencies cases, proving the potential of higher gustiness to create higher air exchange rates $(\mathrm{ACH})$.

\section{Case Study}

The current numerical study deals with the influence of unsteady wind to the instantaneous air exchange rates of a one-story low rise building. The geometry of the parallelepiped model is $10 \mathrm{~m} \times 3 \mathrm{~m} \times 5 \mathrm{~m}$ $(X, \mathrm{Y}, Z)$. Variable leakage areas are simulated in order to verify the impact of the leakage distribution on 
the infiltration rates. The leakages represent cracks around the window frames. The dimensions of each "window" are $0.8 \mathrm{~m} \times 0.8 \mathrm{~m}$. In total, four windows are assumed, all of them normal to the main wind direction, two on the windward and two on the leeward facade (Figure 1).

Figure 1. (a) The building-model and the domain; (b) A symmetry plane (XY) has been used in order to reduce the simulation expenses; (c) The external leakage areas (cracks around windows) and the internal leakage path representing the permeability of the partition wall; (d) Cross section of the domain and the building, the windward facade, the partition wall and the leeward facade are shown.

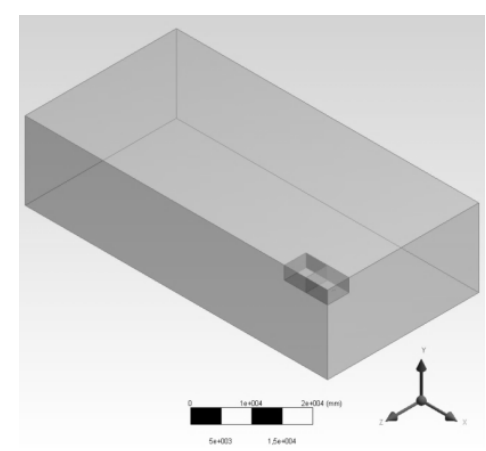

(a)

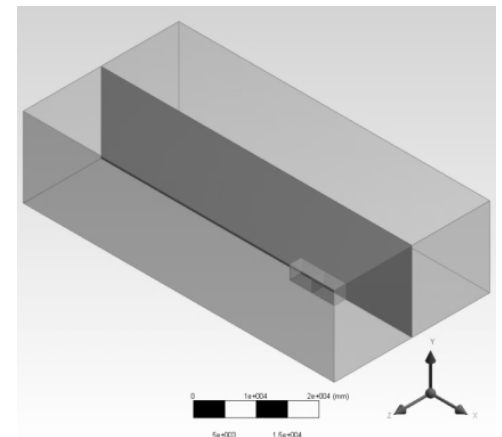

(b)

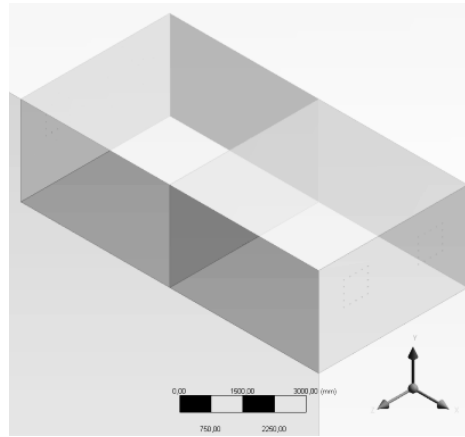

(c)

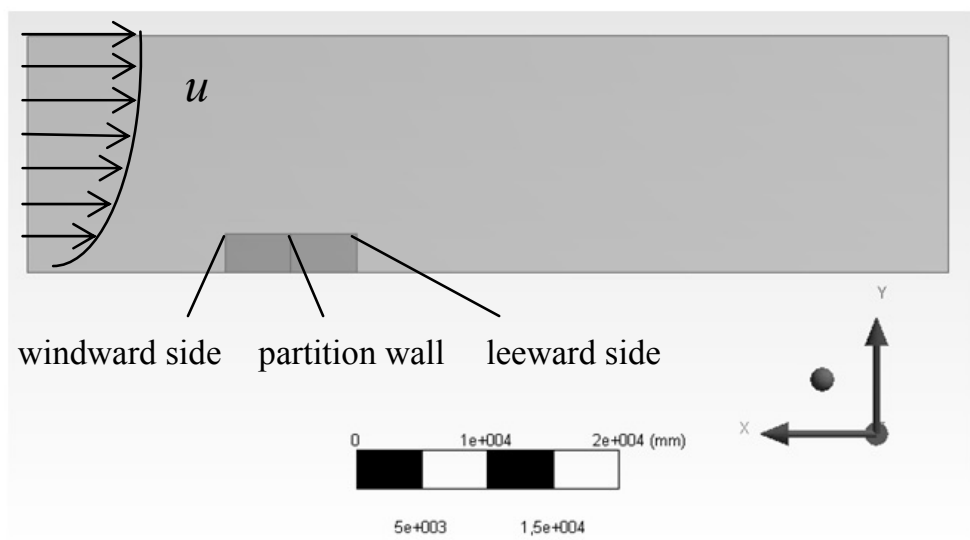

(d)

As mentioned above, the main objective of this paper is to research the impact of the wind gust frequency. The investigation of the role of the latter is important towards the estimation of the wind-driven infiltration of a building in operation. In this context, two gust frequencies, $\Omega_{\text {high }}=0.5 \mathrm{~Hz}$ and $\Omega_{\mathrm{low}}=0.1 \mathrm{~Hz}$, are assumed, while they are implemented in the logarithmic wind profile formula as an additional sinusoidal factor. The wind speed fluctuates in all the frequencies between 0.0005 and $5 \mathrm{~Hz} \mathrm{[43];} \mathrm{therefore,} \mathrm{the} \mathrm{choice} \mathrm{of} \mathrm{the} \mathrm{wind} \mathrm{gust} \mathrm{frequencies} \mathrm{in} \mathrm{this} \mathrm{study} \mathrm{aims} \mathrm{to} \mathrm{study} \mathrm{the}$ middle-range wind frequencies in a logarithmic scale, excluding the extremes of very low or very high frequencies $[30,43]$.

In order to study the role of the internal leakages, five scenarios $\left(S_{1-5}\right)$ are employed (Table 1$)$. The scenario $S_{1}$ refers to a single-room model (without any partition wall), while in all the other cases refer to compartmentalized volume. The cases $\mathrm{S}_{2}, \mathrm{~S}_{3}, \mathrm{~S}_{4}$ and $\mathrm{S}_{5}$ represent different "permeability" of the partition wall in terms of internal leakages. In all the cases, the internal leakages are located on the lower 
level of the partition wall. In the scenarios $\mathrm{S}_{2}, \mathrm{~S}_{3}$, and $\mathrm{S}_{4}$, different amounts of leakages are simulated, while in the last one $\left(\mathrm{S}_{5}\right)$, the assumption of a completely tight wall is employed.

The total external leakage area of the building envelope is selected as $128 \mathrm{~cm}^{2}$, which is approximately equal to $0.01 \%$ of the total exposed model surface. The leakages are located on the windward and on the leeward facade of the building, while no leakage paths are assumed to be on its sides. In order to research the influence of the leakage distribution under unsteady wind conditions and to see their physical connection to the internal leakages, seven cases of leakage distribution are solved. For the representation of the distribution of the external leakages on the windward and the leeward side, a ratio $\alpha$ is defined as follows:

$$
\alpha=\frac{A_{\text {leak,windward }}}{A_{\text {leak,total }}} \times 100(\%)
$$

where $A_{\text {leak,windward }}$ is the area of the leakages located on the windward side of the building and $A_{\text {leak,total }}$ the total leakage area, the sum of the leakages on the windward and the leeward side $\left(=128 \mathrm{~cm}^{2}\right)$. In fact, the ratio $\alpha$ expresses the portion of the envelope leakages that is located on the windward side. The $\alpha$ takes the values: $\alpha=5 \%, \alpha=15 \%, \alpha=30 \%, \alpha=50 \%, \alpha=70 \%, \alpha=85 \%$ and $\alpha=95 \%$.

The simulated building is surrounded by a fetch which plays the role of the domain. The size of the domain is $70 \mathrm{~m} \times 18 \mathrm{~m} \times 40 \mathrm{~m}$. In order to deal with license constraints and to increase the number of the elements used in the mesh and consequently the accuracy of the solver, a symmetry plane has been used. An unstructured mesh of approximately $1.9 \times 10^{6}$ elements $\left(1.4 \times 10^{6}\right.$ tetrahedral, $1 \times 10^{4}$ pyramids, $4 \times 10^{5}$ prisms) and $4.6 \times 10^{5}$ nodes has been used.

Table 1. Internal leakages scenarios $\left(\mathrm{S}_{1-5}\right)$. Partition wall and internal leakages.

\begin{tabular}{ccc}
\hline Scenario & Partition Wall & Internal Leakages \\
\hline Scenario $\mathrm{S}_{1}$ & No & - \\
Scenario $\mathrm{S}_{2}$ & Yes & $8 \mathrm{~cm}^{2}(6.25 \%)^{*}$ \\
Scenario $\mathrm{S}_{3}$ & Yes & $4 \mathrm{~cm}^{2}(3.125 \%)^{*}$ \\
Scenario $\mathrm{S}_{4}$ & Yes & $2 \mathrm{~cm}^{2}(1.5625 \%)^{*}$ \\
Scenario $\mathrm{S}_{5}$ & Yes & 0 \\
\hline
\end{tabular}

\section{Methodology}

The computational fluid dynamics package ANSYS CFX was used for the numerical simulations. The Shear-Stress-Transport (SST) model, a two Equation k- $\omega$ based model [44], has been employed. Pressure distribution around a building is in general important to get correct prediction of the pressure gradients and consequently of the air infiltration across the building envelope. A SST turbulence model has been shown to have good prediction accuracy for the indoor ventilation flow [45]. In addition, other relevant studies on natural ventilation and flows in an enclosure have shown a good agreement between SST model and full scale data, which are better than standard k- $\varepsilon$ and Re-Normalization Group (RNG) k- $\varepsilon$ models [46]. 
At the inlet of the domain, a logarithmic wind profile [47] was assumed, while a sinusoidal term was added in the formula in order to describe the wind unsteadiness. Eventually, the wind profile used for this study is given by the following equation:

$$
\frac{u}{u_{*}}=\frac{1}{\kappa} \ln \left[\frac{Z}{z_{0}}-\Psi_{m}\left(\frac{Z}{L}\right)\right]+2 \sin (2 \pi \Omega t)
$$

where $u$ is the wind velocity at height $z, u *$ is the shear velocity, $\kappa$ von Karman's constant, $z_{0}$ the roughness length and $\Psi_{\mathrm{m}}$ a stability function. The stability function can be evaluated directly from the Monin and Obukhov length $L$, knowing the flux of sensible heat, or indirectly through simultaneous measurements of air temperature profiles [47]. Under neutral stability conditions $\Psi_{m}$ and $\frac{z}{L}$ vanish.

The second term in the right side of the equation describes the "unsteadiness" of the wind, expressed by the gust frequency $\Omega$. As mentioned above, two gust frequencies $\Omega$ have been simulated; $\Omega_{\text {high }}=0.5 \mathrm{~Hz}$ (high frequency) and $\Omega_{\text {low }}=0.1 \mathrm{~Hz}$ (low frequency). The periods $T$ of the two gust frequencies are shown in Figure 2. The longitudinal wind velocity at the inlet of the domain varies from 3.27 to $7.27 \mathrm{~m} \cdot \mathrm{s}^{-1}$. For the steady state (no gust) conditions, the wind velocity is $5.27 \mathrm{~m} \cdot \mathrm{s}^{-1}$. The wind direction angle is normal to the windward side of the building, in all the simulated cases.

Figure 2. Variation of velocity $u$ (at the inlet of the domain and on height $y=1.5 \mathrm{~m}$ ) in respect to time $t$.

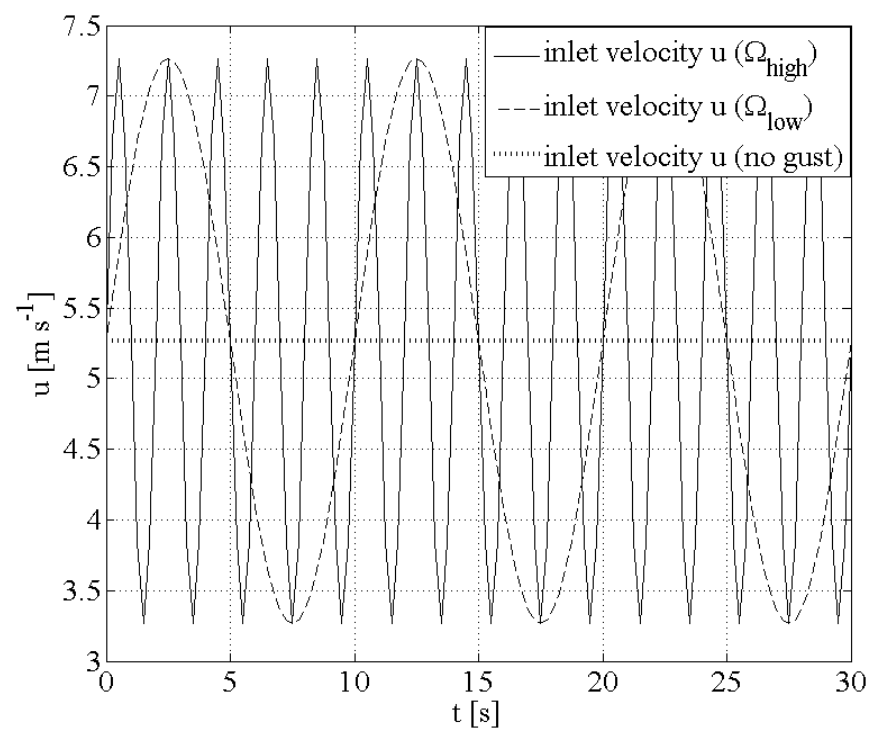

To obtain the dynamics of the building air exchange, the simulations are solved in transient mode. After a mesh sensitivity analysis, a time-step of $0.05 \mathrm{~s}$ has been investigated as sufficient for the length and time scale calculations. The instantaneous mass flow rate $Q_{\mathrm{m}}$ is solved numerically and consequently the instantaneous volumetric flow rates $Q_{v}$ across the leakage areas are calculated, based on the transient, local density field for the interval run time. The equivalent air change rate $\Sigma \mathrm{ACH}$ that represents the "accumulative" air exchanges over $t_{\text {tot }}=1 \mathrm{~h}$ is calculated:

$$
\Sigma \mathrm{ACH}_{i}=\frac{3600}{t_{\text {run }}} * \frac{\left(\int_{0}^{t_{\text {run }}} Q_{v} d t\right)}{V}
$$

where $t_{\text {run }}$ is the total run time per case and $V$ the volume of the enclosure. 
In order to have a magnitude of order of the airtightness level of the building-model, an additional case of simulating a $50 \mathrm{~Pa}$ pressure difference across the envelope was also performed. Establishing a pressure difference of $50 \mathrm{~Pa}$ across the envelope (e.g., using a fan), between indoors and outdoors, has been recognized as a simple and efficient way to characterize the global airtightness of a building, e.g., [20]. The philosophy of the method is based on the rule that a leakier building requires higher airflow rates to pressurize the building to a certain level (e.g., $50 \mathrm{~Pa}$ ), whereas a tighter building requires lower flow rates [48]. The so-called "standard test method for determining air leakage rate by fan pressurization" is described in ASTM Standard E779 [49] and has been widely employed by many national building regulations as a reference tool. The pressurization results at $50 \mathrm{~Pa}$ for the single-compartment building (Scenario $\mathrm{S}_{1}$ ) are shown in the Figure 3 and are compared to the relevant requirements as described in the current Norwegian Building Regulation TEK 10 [50]. The building simulated seems that it would fulfill the airtightness criteria as set for steady-state pressurization conditions, i.e., $n_{50} \leq 1.5 \mathrm{~h}^{-1}$ or $n_{50, \text { small }} \leq 2.5 \mathrm{~h}^{-1}$ for small houses). The CFD pressurization results vary with the leakage distribution ratio $\alpha$ because a change of the magnitude of the leakage area cause a change of the flow conditions (flow exponent, flow coefficient), resulting in a slightly different flow rate.

Figure 3. The maximum allowed air exchanges per hour $(\mathrm{ACH})$ at $50 \mathrm{~Pa}$ pressure difference for different kinds of buildings and the respective result from the CFD-simulated pressurization situation for the building-model of this study.

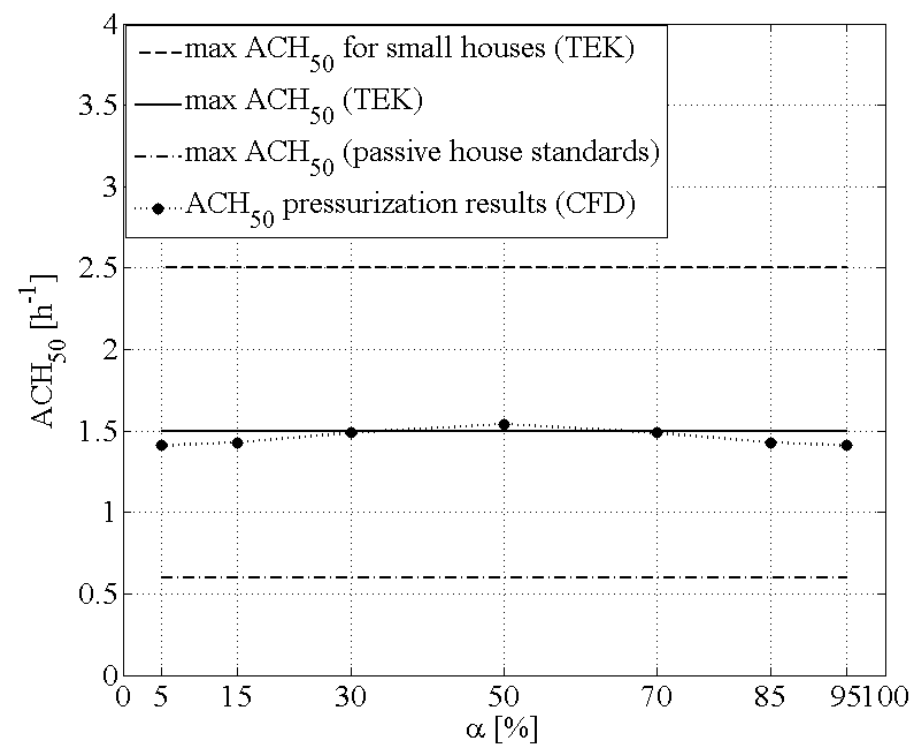

\section{Results and Discussion}

The equivalent air change rates $\Sigma A C H$ against the leakage ratio $\alpha$ for the scenarios $\mathrm{S}_{1}, \mathrm{~S}_{2}, \mathrm{~S}_{3}, \mathrm{~S}_{4}$ and $\mathrm{S}_{5}$ are shown in Figures 4-6. In each graph, two lines appear, representing the rates under high and low wind gust frequency. The solid line shows the variation of the air exchanges because of the high

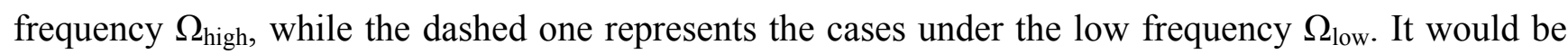
reasonable to claim that the gust frequency of the wind has a significant role, altering the infiltration rates of a building in operation. In addition, the leakage distribution seems that could potentially cause large differences in the $\mathrm{ACH}$ of an enclosure. 
Figure 4. The equivalent air change rate $\Sigma \mathrm{ACH}$ respect to the leakage distribution $\alpha$ for the scenario of the single-room building (no partition wall, Scenario $\mathrm{S}_{1}$ ).

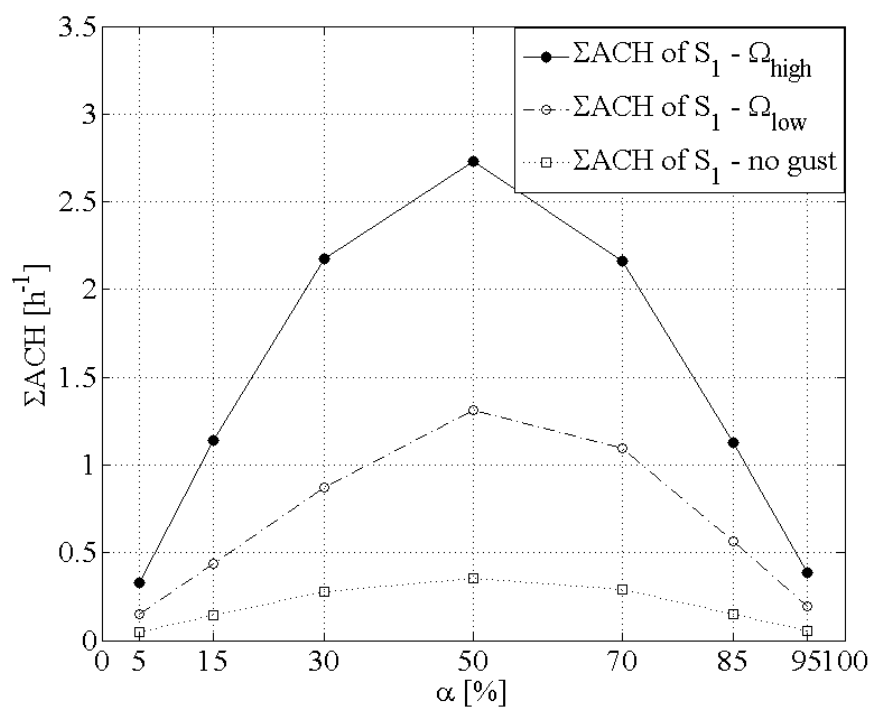

Figure 5. The equivalent air change rate $\Sigma \mathrm{ACH}$ respect to the leakage distribution $\alpha$ for the scenarios of compartmentalized volume and internal leakages on the partition wall. (a) $8 \mathrm{~cm}^{2}$ (Scenario $\left.\mathrm{S}_{2}\right)$; (b) $4 \mathrm{~cm}^{2}\left(\right.$ Scenario $\left.\mathrm{S}_{3}\right)$; and (c) $2 \mathrm{~cm}^{2}$ (Scenario $\left.\mathrm{S}_{4}\right)$.

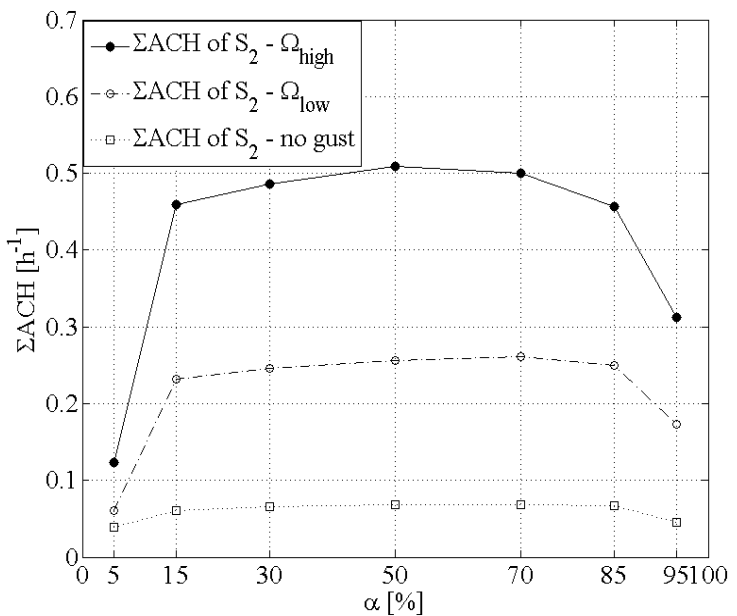

(a)

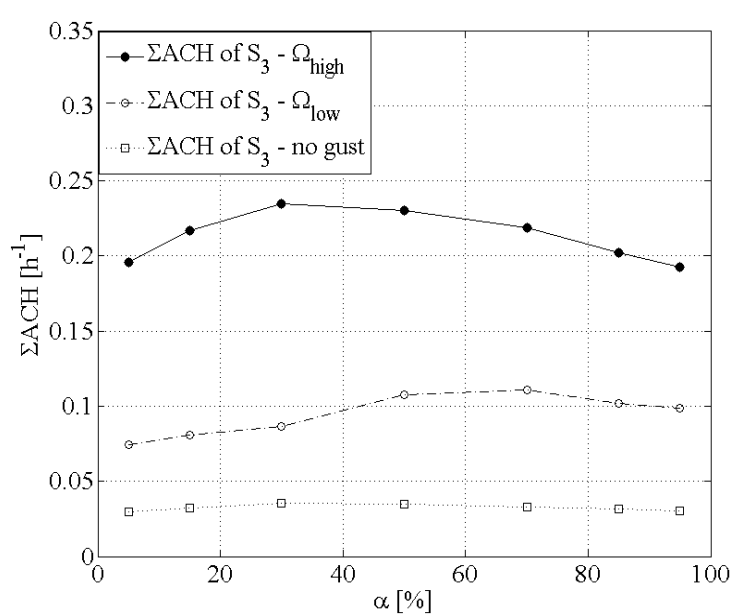

(b)

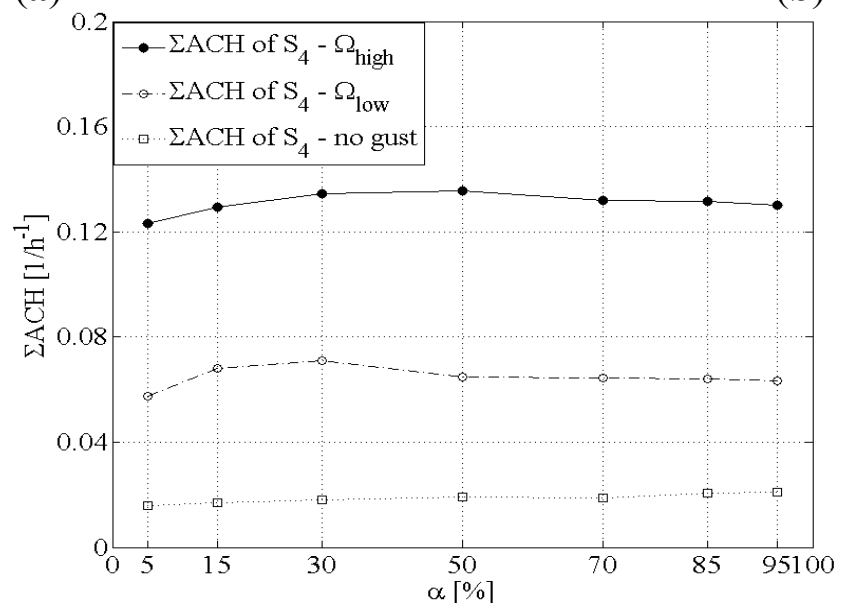

(c) 
Figure 6. The $\Sigma \mathrm{ACH}$ of the two rooms for Scenario $\mathrm{S}_{5}$, when separated by a totally tight (impermeable) partition wall.

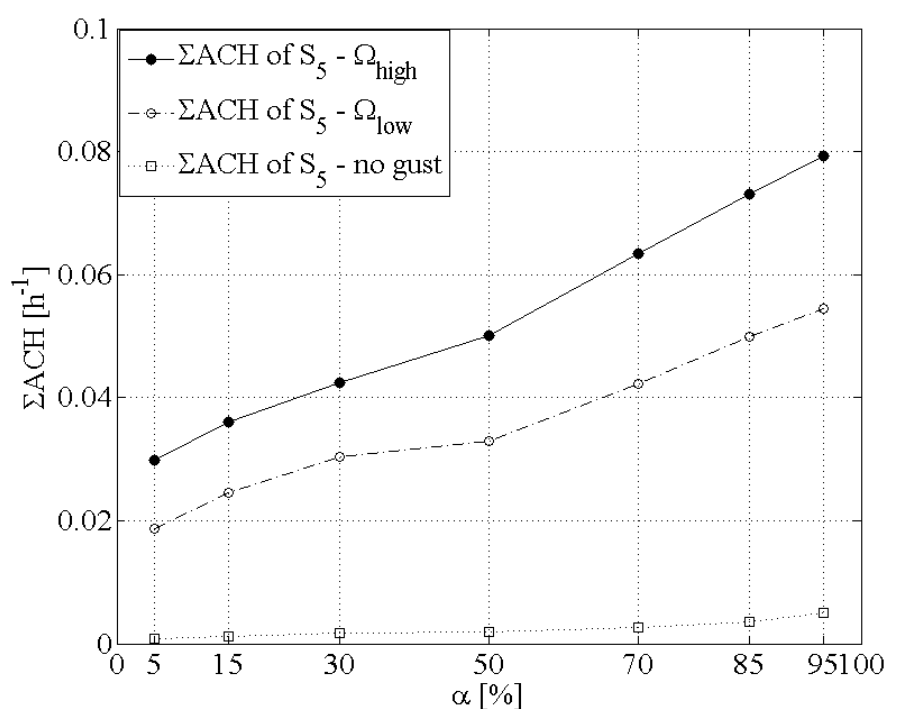

\subsection{Single-Compartment Building-Internal Volume without Partition Wall (Scenario $\left.S_{1}\right)$}

Employing the assumption that the internal volume is single-spaced, Figure 4 shows that the infiltration rates are the highest among the cases studied. The absence of a partition wall leads to a strong air circulation within the one-room-enclosure. This "cross-ventilation" becomes even more dominant when the leakages are equally distributed on the two sides normal to the wind direction (windward and leeward), i.e., $\alpha=50 \%$. For both the high and low gust frequency, the $\mathrm{ACH}$ takes the highest value when $\alpha=50 \%$. In particular, for the $\Omega_{\text {high }}$ the ACH is $2.73 \mathrm{~h}^{-1}$, while for the low frequency $\Omega_{\text {low }}$ the rates are $1.31 \mathrm{~h}^{-1}$. For the steady state conditions, the maximum $\mathrm{ACH}$ is $0.35 \mathrm{~h}^{-1}$. In contrast, the air exchange rates appear to have the lowest values when the external leakages are located either on the windward ( $\alpha=95 \%$ ) or on the leeward facade of the building ( $\alpha=5 \%$ ). Again, the $\Sigma \mathrm{ACH}$ increases in respect to the ratio $\alpha$ until it reaches the maximum value for $\alpha=50 \%(5 \% \leq \alpha \leq 50 \%)$ and then it is getting lower as $\alpha$ increases more $(50 \% \leq \alpha \leq 95 \%)$. The picture is similar for the steady state conditions (Figure 4$)$, but in this case the variation is clearly smaller. The role of the inertia forces of the mass of the enclosure appears to be, in general, weak in the scenario $S_{1}$. Employing the analogy between the air flow in the "enclosure" and a pneumatic spring system and based on the relatively high ACH rates, it would be reasonable to claim that the damping is relatively low. Nevertheless, based on the fairly symmetric picture of the Figure 4, it could be extracted that the damping effect is growing more important when the leakages are mostly located either on the windward or on the leeward side, leading to a reduction of the actual infiltration rates. In those cases, the model behavior is getting more similar to the single-side-infiltration case. The results are consistent with the theoretical study of Etheridge on purpose-designed naturally ventilated buildings [32]. Based on his mathematical model, the effects on the inertia and compressibility are inversely proportional to gust duration and, for a given gust strength, these effects will be more apparent for a gust with a higher amplitude and lower duration.

Moreover, Figure 4 shows the significant impact of the wind unsteadiness on the air exchanges. The higher gust frequency $\Omega_{\text {high }}(0.5 \mathrm{~Hz})$ results in higher equivalent air change rates $\Sigma \mathrm{ACH}$ compared to the lower one $(0.1 \mathrm{~Hz})$ that was employed for this study. Again, when the period $T$ of the wind maxima 
(wind gusts) is reduced by five times (from $T_{\text {low }}=10 \mathrm{~s}$ to $T_{\text {high }}=2 \mathrm{~s}$ ), the ACH increases. Table 2 shows the impact of the increase of the wind gust frequency from 0.1 to $0.5 \mathrm{~Hz}$ on the $\mathrm{ACH}$ rates. In particular, for the scenario $\mathrm{S}_{1}$, depending on how the leakages are distributed in the envelope, the rates alter in a range that varies between $97 \%$ (for $\alpha=95 \%$ ) and $160 \%$ (for $\alpha=15 \%$ ).

Table 2. The increase of $\Sigma \mathrm{ACH}$ for the different leakage-distribution cases when the gust frequency increases from 0.1 to $0.5 \mathrm{~Hz}$.

\begin{tabular}{cccccccc}
\hline \multirow{2}{*}{ Scenario } & \multicolumn{7}{c}{ Increase of $\mathbf{\Sigma A C H}$} \\
\cline { 2 - 8 } & $\boldsymbol{\alpha}=\mathbf{5 \%}$ & $\boldsymbol{\alpha}=\mathbf{1 5 \%}$ & $\boldsymbol{\alpha}=\mathbf{3 0 \%}$ & $\boldsymbol{\alpha}=\mathbf{5 0 \%}$ & $\boldsymbol{\alpha}=\mathbf{7 0 \%}$ & $\boldsymbol{\alpha}=\mathbf{8 5 \%}$ & $\boldsymbol{\alpha}=\mathbf{9 5 \%}$ \\
\hline Scenario 1 & $119 \%$ & $160 \%$ & $150 \%$ & $108 \%$ & $97 \%$ & $99 \%$ & $97 \%$ \\
Scenario 2 & $103 \%$ & $98 \%$ & $97 \%$ & $99 \%$ & $91 \%$ & $82 \%$ & $80 \%$ \\
Scenario 3 & $163 \%$ & $170 \%$ & $171 \%$ & $114 \%$ & $98 \%$ & $98 \%$ & $96 \%$ \\
Scenario 4 & $114 \%$ & $90 \%$ & $90 \%$ & $109 \%$ & $104 \%$ & $105 \%$ & $105 \%$ \\
Scenario 5 & $59 \%$ & $47 \%$ & $40 \%$ & $52 \%$ & $50 \%$ & $46 \%$ & $46 \%$ \\
\hline
\end{tabular}

The results show that the leakage distribution can cause large variations in $\mathrm{ACH}$ rates, especially under unsteady wind conditions. Table 3 shows the standard deviation $\sigma$ of the $\Sigma \mathrm{ACH}$ for the five enclosure-scenarios studied under the two gust frequencies employed. In the Scenario $\mathrm{S}_{1}$, the standard deviation is high, as $\sigma=0.936$ and $\sigma=0.446$ for the $\Omega_{\text {high }}$ and $\Omega_{\text {low }}$, respectively, implying the important influence of the leakage distribution on the air exchange rates of a building in operation. Especially for the high gust frequency, it would be reasonable to claim that the leakage distribution raises an uncertainty issue for the estimation of the realistic infiltration rates of a building.

Table 3. The standard deviation $\sigma$ of $\Sigma \mathrm{ACH}$ and the respective arithmetic mean when the $\mathrm{ACH}$ is considered in respect to the leakage distribution $\alpha$.

\begin{tabular}{cccc}
\hline \multirow{2}{*}{ Scenario } & \multicolumn{3}{c}{ Standard Deviation $\boldsymbol{\sigma}$ (and the Arithmetic Mean) of $\boldsymbol{\Sigma} \mathbf{A C H}$} \\
\cline { 2 - 4 } & $\boldsymbol{\Omega}_{\text {high }}$ & $\boldsymbol{\Omega}_{\text {low }}$ & No Gust \\
\hline Scenario 1 & $0.936(1.435)$ & $0.446(0.661)$ & $0.121(0.188)$ \\
Scenario 2 & $0.141(0.406)$ & $0.073(0.211)$ & $0.012(0.059)$ \\
Scenario 3 & $0.017(0.213)$ & $0.014(0.094)$ & $0.002(0.032)$ \\
Scenario 4 & $0.004(0.131)$ & $0.004(0.065)$ & $0.002(0.019)$ \\
Scenario 5 & $0.019(0.053)$ & $0.013(0.036)$ & $0.001(0.002)$ \\
\hline
\end{tabular}

\subsection{Building with Partition Wall with Internal Leakages (Scenarios $S_{2}, S_{3}$ and $S_{4}$ )}

Starting with Scenario $\mathrm{S}_{2}$, all the cases presented hereinafter refer to a model in which a partition wall has been added. In total, there are four scenarios with compartmentalized models. In particular, in three of them $\left(\mathrm{S}_{2}, \mathrm{~S}_{3}\right.$ and $\left.\mathrm{S}_{4}\right)$, internal leakages have been assumed on the partition wall. In Figure 5a-c, the equivalent air change rates $\Sigma \mathrm{ACH}$ for the Scenarios $\mathrm{S}_{2}, \mathrm{~S}_{3}$ and $\mathrm{S}_{4}$ are shown in respect to the leakage distribution ratio $\alpha$.

It would be reasonable to claim that the existence of a relatively tight partition wall has a drastic impact (drop) on the air change rates (Figure $5 \mathrm{a}-\mathrm{c}$ ). The $\Sigma \mathrm{ACH}$ appear (for both the gust frequencies $\Omega_{\text {high }}$ and $\Omega_{\text {low }}$ ) to be much lower compared to Scenario $S_{1}$ ). Although a "cross ventilation" takes place even in those cases (in analogy to $S_{1}$ ), the level of tightness of the wall in combination with the inertia 
forces of the mass of the internal volume increases the damping, resulting in significantly lower infiltration rates. Nevertheless, the impact of the wind gust frequency is important (as in Scenario $S_{1}$ ) in all the cases presented in this section (Table 2). However, in general, the leakage distribution affects less the air exchanges in those three scenarios compared to Scenario $\mathrm{S}_{1}$ (Table 3).

As mentioned above, the partition wall and the compartmentalization of the initial enclosure reduces dramatically the $\mathrm{ACH}$. Scenario $\mathrm{S}_{2}$ represents the model with a partition wall on which internal leakages of $8 \mathrm{~cm}^{2}$ have been simulated. The rates have been calculated as $\Sigma \mathrm{ACH}=0.51 \mathrm{~h}^{-1}$ and $\Sigma \mathrm{ACH}=0.26 \mathrm{~h}^{-1}$ for the $\Omega_{\text {high }}$ and the $\Omega_{\text {low }}$, respectively, while for the steady state no-gust conditions $\Sigma$ ACH $=0.07 \mathrm{~h}^{-1}$ (Figure 5a). This corresponds to approximately a five-fold drop compared to the respective rates in Scenario $\mathrm{S}_{1}$. The maximum values occur when $\alpha=50 \%$ and $\alpha=70 \%$ for the high and low gust frequencies, respectively. The internal leakages result in a similar symmetrical picture regarding the equivalent air exchanges; the lowest values of $\Sigma \mathrm{ACH}$ occur when the external leakages are concentrated either on the windward or on the leeward facade of the building ( $\alpha=95 \%$ or $\alpha=5 \%$, respectively). However, the standard deviation is much smaller in this case, implying a more "mild" impact of the leakage distribution on the ACH (Table 3). Especially, if the extreme sub-cases of $\alpha=95 \%$ or $\alpha=5 \%$ are excluded (Figure 5a), the air infiltration rates vary relatively small in respect to the ratio $\alpha$. In contrast, the influence of the wind gust frequency remains significant, as the change from 0.1 to $0.5 \mathrm{~Hz}$ results in an increase of $\mathrm{ACH}$ that increases from $80 \%$ (for $\alpha=95 \%$ ) to $103 \%$ (for $\alpha=5 \%$ ) (Table 2).

A further reduction of the internal leakages on the partition wall results in an even larger drop of the $\mathrm{ACH}$. In Scenario $\mathrm{S}_{3}$ the internal leakages have been scaled down to $4 \mathrm{~cm}^{2}$, half than in the previous Scenario $\mathrm{S}_{2}$. Now the maximum values of the rates have been calculated as $\Sigma A C H=0.23 \mathrm{~h}^{-1}$ and $\Sigma \mathrm{ACH}=0.11 \mathrm{~h}^{-1}$ for the $\Omega_{\text {high }}$ and the $\Omega_{\text {low }}$, respectively, and $\Sigma \mathrm{ACH}=0.03 \mathrm{~h}^{-1}$ for the no-gust wind conditions (Figure $5 b$ ). The impact of the leakage distribution is getting even smaller in Scenario $\mathrm{S}_{3}$, as shown in Table 3. However, the influence of the gust frequency seems to be very important (Table 2).

Finally, by controlling the internal leakages even more and reducing them to $2 \mathrm{~cm}^{2}$, a further reduction of the $\mathrm{ACH}$ is achievable. In particular, in Scenario $\mathrm{S}_{4}$, the maximum infiltration rates are $\Sigma \mathrm{ACH}=0.14 \mathrm{~h}^{-1}$ and $\Sigma \mathrm{ACH}=0.07 \mathrm{~h}^{-1}$ for the $\Omega_{\text {high }}$ and the $\Omega_{\text {low }}$, respectively, while $\Sigma \mathrm{ACH}=0.02 \mathrm{~h}^{-1}$ for the steady state conditions (Figure $5 \mathrm{c}$ ). The results appear to be quite "uniform" in respect to the leakage distribution ratio $\alpha$, as reflected on the standard deviation $\sigma$, which is small for both the high and the low wind gust frequency (Table 3). Under steady state conditions, the leakage distribution does not significantly alter the air exchanges, especially in Scenarios $\mathrm{S}_{3}$ and $\mathrm{S}_{4}$. Based on Table 3, the standard deviation $\sigma$ for the no-gust wind conditions is very small, showing that it is of no consequence whether the larger leakage area occurs on the windward or on the leeward side. These findings are in agreement with a study presented by Etheridge [34]. Even for Scenario $\mathrm{S}_{2}$, the infiltration rates do not vary significantly. An exception can be reported for the extreme cases of $\alpha=95 \%$ and $\alpha=5 \%$, which are very close to a single-side ventilation situation and, hence, it is not now only the pressure difference between windward and leeward side that matters but also the absolute magnitude on each side.

In contrast, the frequency affects the air exchanges, as there is an increase in the ACH that increases from $96 \%$ to $114 \%$ when the frequency switches from 0.1 to $0.5 \mathrm{~Hz}$. Under mild wind gust frequency conditions, the relatively tight partition element could potentially result in low air change rates. Thus, internal leakages and wind gust frequency seem to be critical parameters for the estimation of the operational wind-driven infiltration rates of a building. 


\subsection{Building with Impermeable Partition-Partition Wall without Internal Leakages (Scenario $\left.S_{5}\right)$}

The role of the internal leakages on the air exchange rates estimation becomes even clearer in Scenario $\mathrm{S}_{5}$. In this case, a hypothesis of a totally tight partition wall is employed. In Figure 6 , the calculated air exchanges over one hour are shown for the high and low wind gust frequency as well as for the steady state conditions. Controlling the internal leakages and assuming that the partition wall is completely tight, the air change rates become even lower compared to all the previous scenarios presented in the paper. The highest values are now $\Sigma \mathrm{ACH}=0.08 \mathrm{~h}^{-1}$ and $\Sigma \mathrm{ACH}=0.05 \mathrm{~h}^{-1}$ for the $\Omega_{\text {high }}$ and the $\Omega_{\text {low }}$, respectively, while for the no-gust steady state conditions $\Sigma \mathrm{ACH}=0.005 \mathrm{~h}^{-1}$ (Figure 6). The impact of the gust frequency is now moderate in this scenario. As shown in Table 2, the increase in the $\mathrm{ACH}$ varies between $40 \%$ and $59 \%$, when the frequency alters from 0.1 to $0.5 \mathrm{~Hz}$. The results are consistent with the airflow spectra of Haghighat et al. [33] showing that in a single-side infiltration case, a higher frequency might be necessary to cause a certain level of airflow that is possible with a lower frequency in a two "openings" scenario.

The rates increase in respect to the leakage distribution ratio $\alpha$, so that the maximum values of $\mathrm{ACH}$ take place when the leakages are mostly located on the windward facade of the model $(\alpha=95 \%)$. The latter is reflected in the standard deviations $\sigma$ of the rates, which are higher than the respective ones in Scenario $\mathrm{S}_{4}$ and fairly equal to those of Scenario $\mathrm{S}_{3}$ (Table 3 ).

The tight partition wall results in the total compartmentalization of the volume into two spaces. The inertia forces of the mass of the windward "room" are in this case higher because of the single-side infiltration and the compressibility of the volume decreases. The second "room" has gotten "isolated" in this case, so there is not significant air exchange through the leeward leakages. The combination of those facts leads to the dramatic drop of the rates as shown in the Figure 6.

If the leakages are mostly located on the leeward facade or even equally distributed between the windward and the leeward side of the building, the operational air is exchanged, especially under the low gust frequency $\Omega_{\text {low }}$. Nevertheless, even for the $\Omega_{\text {high }}$ the infiltration rates are now lower, implying that a high control of internal leakages can significantly contribute to eliminating the impact of the gust frequency. According to Jones et al. [42] assuming impermeable partition elements between dwellings (floor, ceiling and side walls) leads to higher estimated infiltration rates compared to when these elements are permeable. Their results are logical, because they show that the typical "cross ventilation" situation when assuming leakages only on the windward and leeward side is getting "disturbed" (and the airflow deviated) by the permeability of the partition elements resulting in smaller air exchanges through the leakages on the windward and the leeward sides. However, their findings cannot be straightforward comparable to the current study, as in the latter, the upper, lower and side elements are assumed to be completely tight in all the scenarios and only the airflow in the axis windward-leeward side is under investigation. A further extension of the current study in order to include internal leakages on more than one wall, different possible airflow patterns within an enclosure and leakages distributed on more elements than the ones normal to the wind direction would provide a more holistic perspective of infiltration rates and their connection with the internal leakage paths.

Finally, Table 4 summarizes the highest and lowest values of the infiltration rates for the high wind gust frequency $\Omega_{\text {high }}$, the low frequency $\Omega_{\text {low }}$ and the no-gust steady state conditions, in all the scenarios 
of compartmentalization/partition-wall-permeability. The values of the leakage distribution ratio $\alpha$ to that of when the max and min values occur are given in parenthesis.

Table 4. The max and min values of $\Sigma \mathrm{ACH}$ for $\Omega_{\text {high }}, \Omega_{\text {low }}$ and the steady state conditions.

\begin{tabular}{lcccccc}
\hline \multicolumn{7}{c}{ max and min $\boldsymbol{\Sigma}$ ACH } \\
\hline \multirow{2}{*}{ Scenario } & \multicolumn{2}{c}{$\boldsymbol{\Omega}_{\text {high }}$} & \multicolumn{2}{c}{$\boldsymbol{\Omega}_{\text {low }}$} & \multicolumn{2}{c}{ Steady state, no gust } \\
\cline { 2 - 7 } & $\mathbf{m a x}$ & $\mathbf{m i n}$ & $\mathbf{m a x}$ & $\mathbf{m i n}$ & $\max$ & min \\
\hline Scenario 1 & $2.73(50 \%)$ & $0.33(5 \%)$ & $1.31(50 \%)$ & $0.15(5 \%)$ & $0.35(50 \%)$ & $0.05(5 \%)$ \\
Scenario 2 & $0.51(50 \%)$ & $0.12(5 \%)$ & $0.26(70 \%)$ & $0.06(5 \%)$ & $0.07(50 \%)$ & $0.04(5 \%)$ \\
Scenario 3 & $0.23(30 \%)$ & $0.19(95 \%)$ & $0.11(70 \%)$ & $0.07(5 \%)$ & $0.04(30 \%)$ & $0.03(5 \%)$ \\
Scenario 4 & $0.14(50 \%)$ & $0.12(5 \%)$ & $0.07(95 \%)$ & $0.06(5 \%)$ & $0.02(95 \%)$ & $0.015(5 \%)$ \\
Scenario 5 & $0.08(95 \%)$ & $0.03(5 \%)$ & $0.05(95 \%)$ & $0.02(5 \%)$ & $0.005(95 \%)$ & $0.001(5 \%)$ \\
\hline
\end{tabular}

\section{Conclusions}

A low rise building with variable leakage areas on the windward and the leeward side was simulated and studied numerically under unsteady wind conditions. The wind-driven infiltration rates under two different wind gust frequencies were calculated and compared to steady state conditions. The gust frequency seems to be a critical parameter, as it results in an increase of air exchanges of a building in operation.

The leakage distribution affects the infiltration rates especially in the single-compartment scenario, where strong cross "ventilation" takes place. The most severe situation appears when the leakage areas on the windward and the leeward facade are of the same magnitude of order. Again, the more equal the leakages are, the higher the distribution of air exchanges.

The existence of relatively tight internal walls in a double-compartment building decreases drastically the infiltration rates, compared to the single-space model. In particular, controlling the internal leakages, the drop of the $\mathrm{ACH}$ becomes significant, resulting in rates that could be considered as "acceptable" in a building-regulations context. In those cases, the influence of the gust frequency is still very important, while the role of the leakage distribution is moderate. By creating more tightness in the partition wall, the $\mathrm{ACH}$ decreases even more, constraining the impact of the gust frequency.

Leakage distribution creates uncertainty in the estimation of wind-driven infiltration. In addition, the wind gust frequency causes significant variations in the $\mathrm{ACH}$ of a building in operation. The paper also highlights that the control of the internal leakages should be a parameter more deeply studied. In decreasing the infiltration rates, the "component" of the internal leakage paths should also be considered as important, as well as the leakages of the envelope. Furthermore, fulfilling a sufficient airtightness level of the internal building elements could also moderate the impact of wind gust frequency.

The study raises issues regarding uncontrolled leakages in the building envelope. The detection of leakages and their distribution ought to be considered as critical factors, while wind unsteadiness results in significant variations in wind-driven infiltration. Furthermore, internal leakages seem to play an important role in the nearly zero-energy building target. Further research needs to be done in order to investigate the connection between internal and external leakages in a more detailed way. 


\section{Acknowledgments}

The current study has been financed by the Norwegian University of Life Sciences under project number 12351027.

\section{Conflicts of Interest}

The authors declare no conflict of interest.

\section{References}

1. Jackman, P. Heat loss in buildings as a result of infiltration. Build. Serv. Eng. 1974, 42, 6-15.

2. Kirkwood, R.C. Fuel consumption in industrial buildings. Build. Serv. Eng. 1977, 45, $23-31$.

3. Nevrala, D.J.; Etheridge, D.W. Natural Ventilation in Well-Insulated Houses. In Proceedings of International Centre for Heat and Mass Transfer, International Seminar, UNESCO, Dubrovnik, Croatia, 29 August-2 September 1977; Volume 3.

4. Blomsterberg, A.K.; Harrje, D.T. Approaches to evaluation of air infiltration energy losses in buildings. ASHRAE Trans. 1979, 85, 797-815.

5. Caffey, G.E. Residential air infiltration. ASHRAE Trans. 1979, 85, 919-926.

6. Persily, A. Understanding Air Infiltration in Homes; Report PU/CEES No. 129; Princeton University Center for Energy and Environmental Studies: Princeton, NJ, USA, 1982.

7. Anderlind, G. Energy Consumption Due to Air Infiltration. In Proceedings of the 3rd ASHRAE/DOE/BTECC Conference on Thermal Performance of Exterior Envelopes of Buildings, Clear Water Beach, FL, USA, 1985; pp. 201-208.

8. Claridge, D.E.; Bhattacharyya, S. The measured energy impact of "infiltration" in a test cell. ASME J. Sol. Energy Eng. 1990, 112, 132-139.

9. Liu, M. Study of Air Infiltration Energy Consumption. Ph.D. Thesis, Department of Mechanical Engineering, Texas A\&M University, College Station, TX, USA, 1992.

10. Jokisalo, J.; Kalamees, T.; Kurnitski, J.; Eskola, L.; Jokiranta, K.; Ninha, J. A comparison of measured and simulated air pressure conditions of a detached house in a cold climate. J. Build. Phys. 2008, 32, 67-89.

11. Shaw, C.Y. A Correlation between Air Infiltration and Air Tightness for Houses in a Developed Residential Area; National Research Council Canada: Ottawa, OT, Canada, 1981; Volume 87, pp. 333-341.

12. Allard, F. Natural Ventilation in Buildings: A Design Handbook; James \& James: London, UK, 1998.

13. Santamouris, M.; Wouters, P. Building Ventilation - The State of the Art; Earthscan, INIVE-AIVC: London, UK, 2006.

14. Lstiburek, J.; Pressnail, K.; Timusk, J. Air pressure and building envelopes. J. Build. Phys. 2002, 26, 53-91.

15. Liddament, M.W. Air Infiltration Calculation Techniques: An Applications Guide; AIVC: Bracknell, England, UK, 1986.

16. Langmans, J.; Klein, R.; Roels, S. Hygrothermal risks of using exterior air barrier systems for highly insulated light weight walls: A laboratory investigation. Build. Environ. 2012, 56, 192-202. 
17. Etheridge, D.W.; Sandberg, M. Building Ventilation: Theory and Measurement; Wiley: Chichester, UK, 1996.

18. Lyberg, M.D. Basic air infiltration. Build. Environ. 1997, 32, 95-100.

19. Orme, M. Applicable Models for Air Infiltration and Ventilation Calculations; Air Infiltration and Ventilation Centre: Coventry, UK, 1999.

20. Orme, M.; Liddament, M.W.; Wilson, A. Numerical Data for Air Infiltration and Natural Ventilation Calculations; Air Infiltration and Ventilation Centre: Coventry, UK, 1998.

21. Sherman, M. Estimation of infiltration from leakages and climate indicators. Energy Build. 1987, $10,81-86$.

22. Sherman, M.H. The use of blower-door data. Indoor Air 1995, 5, 215-224.

23. Brownell, C. Infiltration Heat Recovery. BA Thesis, Duke University, Durham, NC, USA, 2002.

24. Vickery, B.J. Gust-Factors for internal-pressures in low rise buildings. J. Wind Eng. Ind. Aerodyn. 1986, 23, 259-271.

25. Cummings, J.B.; Withers, C.R.; Moyer, N.; Fairey, P.; McKendry, B. Uncontrolled Air Flow in Non-Residential Buildings-Final Report; Florida Energy Office-Department of Community Affairs: Tallahassee, FL, USA, 1996.

26. Haghighat, F.; Brohus, H.; Rao, J. Modelling air infiltration due to wind fluctuations-A review. Build. Environ. 1999, 35, 377-385.

27. Etheridge, D.W. Unsteady Wind Effects in Natural Ventilation Design. In Proceedings of the CIBSE National Conference, Harrogate, UK, 4-5 October 1999.

28. Chaplin, G.C.; Randall, J.R.; Baker, C.J. The turbulent ventilation of a single opening enclosure. J. Wind Eng. Ind. Aerodyn. 2000, 85, 145-161.

29. Karava, P.; Stathopoulos, T.; Athienitis, A.K. Impact of internal pressure coefficients on wind driven ventilation analysis. Int. J. Vent. 2006, 5, 53-66.

30. Hill, J.E.; Kusuda, T. Dynamic characteristics of air infiltration. ASHRAE Trans. 1975, 81, $168-185$.

31. Cockroft, J.P.; Robertson, P. Ventilation of an enclosure through a single opening. Build. Environ. 1976, 11, 29-35.

32. Etheridge, D.W. Unsteady flow effects due to fluctuating wind pressures in natural ventilation design-Instantaneous flow rates. Build. Environ. 2000, 35, 321-337.

33. Haghighat, F.; Rao, J.; Fazio, P. The influence of turbulent wind on air change rates-A modelling approach. Build. Environ. 1991, 26, 95-109.

34. Etheridge, D.W. Modeling of air infiltration in single and multi-cell buildings. Energy Build. 1988, 10, 185-192.

35. Dubrul, C. Inhabitants Behavior with Respect to Ventilation; Air Infiltration and Ventilation Centre: Coventry, UK, 1988; p. 63.

36. Oh, J.H.; Kopp, G.A.; Inculet, D.R. The UWO contribution to the NIST aerodynamic database for wind loads on low buildings: Part 3. Internal pressures. J. Wind Eng. Ind. Aerodyn. 2007, 95, 755-779.

37. Chan, W.R.; Price, P.N.; Sohn, M.D.; Gadgil, A.J. Analysis of U.S. Residential Air Leakage Database. Available online: http://escholarship.org/uc/item/6pk6r4gs (accessed on 28 February 2014). 
38. Kalamees, T.; Korpi, M.; Eskola, L.; Kurnitski, J.; Vinha, J. The Distribution of the Air Leakage Places and Thermal Bridges in Finnish Detached Houses and Apartment Buildings. In Proceedings of the 8th Symposium on Building Physics in the Nordic Countries (NSB2008), Copenhagen, Denmark, 16-18 June 2008; pp. 1095-1102.

39. Guha, T.K.; Sharma, R.N.; Richards, P.J. Internal pressure dynamics of a leaky building with a dominant opening. J. Wind Eng. Ind. Aerodyn. 2011, 99, 1151-1161.

40. Lowe, R.J. Ventilation strategy, energy use and $\mathrm{CO}_{2}$ emissions in dwellings-A theoretical approach. Build. Serv. Eng. Res. Technol. 2000, 21, 179-185.

41. Aaltonen, A.; Lähdesmäki, K.; Vinha, J. Air Tightness of Structural Elements and Internal Air Leakages in a Multi-Apartment Building. In Proceedings of the 9th Nordic Symposium on Building Physics (NSB2011), Tampere, Finland, 29 May-2 June 2011; pp. 79-86.

42. Jones, B.; Das, P.; Chalabi, Z.; Davies, M.; Hamilton, I.; Lowe, R.; Milner, J.; Ridley, I.; Shrubsole, C.; Wilkinson, $\mathrm{P}$. The effect of party wall permeability on estimations of infiltration from air leakage. Int. J. Vent. 2013, 12, 17-29.

43. Thomas, G. Identification of Trensfer Functions for Wind-Induced Pressures on Prismatic Buildings. Available online: http://repositories.tdl.org/tdl-ir/handle/2346/20680 (accessed on 28 February 2014).

44. Menter, F.R. Two-equation eddy-viscosity turbulence models for engineering applications. AIAA J. 1994, 32, 1598-1605.

45. Ramponi, R.; Blocken, B.J.E. CFD simulation of cross-ventilation for a generic isolated building: Impact of computational parameters. Build. Environ. 2012, 53, 34-48.

46. Guha, T.K.; Sharma, R.N.; Richards, P.J. CFD Modeling of Wind Induced Mean and Fluctuating External Pressure Coefficients on the Texas Technical University Building. In Proceedings of the European African Computational Wind Engineering 5, Florence, Italy, 19-23 July 2009.

47. Grimenes, A.A.; Thue-Hansen, V. Annual variation of surface roughness obtained from wind profile measurements. Theor. Appl. Climatol. 2004, 79, 93-102.

48. Chan, W.R.; Nazaroff, W.W.; Price, P.N.; Sohn, M.D.; Gadgil, A.J. Analyzing a database of residential air leakage in the United States. Atmos. Environ. 2005, 39, 3445-3455.

49. ASTM Standard E779. Standard Test Method for Determining Air Leakage by Fan Pressurization; American Society of Testing and Materials: Philadelphia, PA, USA, 1999.

50. Byggteknisk forskrift-TEK 10, FOR 2010-03-26 nr 489: Forskrift om Tekniske Krav til Byggverk (Byggteknisk forskrift); Direktoratet for byggkvalitet: Oslo, Norway, 2010 (in Norwegian).

(C) 2014 by the authors; licensee MDPI, Basel, Switzerland. This article is an open access article distributed under the terms and conditions of the Creative Commons Attribution license (http://creativecommons.org/licenses/by/3.0/). 